\title{
Editorial
}

\section{The pointy end of the stick: managing biological invasions}

\author{
Marnie L. Campbell \\ Central Queensland University, Bryan Jordan Drive, PO Box 1319, Gladstone, 4680, Queensland, Australia \\ E-mail:m.campbell@cqu.edu.au
}

Published online: 18 February 2013

Charles Elton identified the growing instance of human-mediated species transfers as a potential ecological threat in his seminal treatise in 1958. Since that time, our understanding and management practice has developed, at times in fits and starts. After more than 50 years, we can now say that the study of biological invasions is acknowledged as a unique and valid scientific sub-discipline, with scores of freshly minted doctoral students and academic positions attributed to the study of introductions. Unfortunately a disjunct has arisen between the academically oriented scientific discipline of invasion ecology and the applied focus of invasion management and policy (often referred to as biosecurity).

Although an increased focus on introduced species science literature has been apparent in the last few decades, as evidenced by the creation of specialty journals to service the subdiscipline, the dissemination of how to best manage these issues has, for the most part, been ignored in the biological invasions literature. The biological invasions literature has increasingly shifted towards greater attention to underpinning theory, leaving a growing gap for managers. This has led to a variety of issues, specifically the replication of applied research (and therefore expenditure) where managers are unaware of relevant research on biological invasions elsewhere. This is potentially a waste of valuable and diminishing resources: 1) valuable budget resources, where globally governments are experiencing decreasing budget investments for environmental and conservation outcomes; 2) valuable time in a time sensitive/crisis driven discipline, with researchers reinventing the applied science wheel of biosecurity/managing biological invasions as they forge ahead with ways to tackle the biological invasions problem in their region. I applaud the efforts of researchers and managers seeking information and knowledge to aid their biosecurity efforts, but I'm aware that research is often repeated instead of building upon and improving what has already occurred. In part, this is attributable to a lack of journal outlets willing to present practical, management focused scholarly research that will build a body of applied biosecurity research.

2013 marks the next step in the continuing evolution of the international journal Management of Biological Invasions (MBI). MBI has joined Aquatic Invasions (AI) and BioInvasions Records (BIR) at REABIC - the Regional EuroAsian Biological Invasions Centre; an institute that focusses on applied research on the ecology and management of biological invasions. AI and BR have started to address the gap between fundamental and applied invasion research, with MBI now stepping fully into this breach with an explicit focus on servicing the requirements of management oriented research.

REABIC acknowledges that the issue of biological invasions requires both a theoretical and applied focus - working across multiple disciplines to understand processes and identify management priorities and interventions. The REABIC journals, especially MBI, aim to fill this gap by translating theoretical bioinvasions science into applied scientific/management outputs that can be readily used for management and policy. 
How will we get there? As the new MBI Editor-in-Chief I have invited an Editorial Team that provides a broad range of discipline and management oriented interests and experience. Together, we will seek to be a vibrant research outlet that will build a wealth of knowledge in support of biosecurity management and policy.

As Editor-in-Chief I will use this editorial to identify critical issues to help shape the science of managing biological invasions. In addition, invited editorials will provide insights into the current state of knowledge and direction for specific aspects of managing biological invasions, exploring various aspects from both research and management perspectives, in point and counter-point viewpoint pieces. In so doing, I hope that we will build interest, influence awareness and increase our shared knowledge base to improve the management of biological invasions. To begin this process, Dr. Stelios Katsanevakis and colleagues have provided a Viewpoint article to this edition that focusses on the implementation of European policies for introduced species (Katsanevakis et al. 2013).

Marnie L. Campbell

Editor-in-Chief

\section{References}

Elton C (1958) The Ecology of Invasions by Animals and Plants. Methuen, London, $181 \mathrm{pp}$

Katsanevakis S, Genovesi P, Gaiji S, Hvid HN, Roy H, Nunes AL, Aguado FS, Bogucarskis K, Debusscher B, Deriu I, Harrower C, Josefsson M, Lucy FE, Richards G, Trichkova T, Vanderhoeven S, Zenetos A, Cardoso AC (2013) Implementing the European policies for alien species networking, science, and partnership in a complex environment. Management of Biological Invasions 4: 3-6, http://dx.doi.org/10.3391/mbi.2013.4.1.02 